\title{
The effect of a paint bake treatment on joint performance in friction stir spot welding AA6111-T4 sheet using a pinless tool
}

DOI:

10.1016/j.matchemphys.2013.05.073

\section{Document Version}

Accepted author manuscript

Link to publication record in Manchester Research Explorer

Citation for published version (APA):

Chen, YC., Liu, SF., Bakavos, D., \& Prangnell, PB. (2013). The effect of a paint bake treatment on joint performance in friction stir spot welding AA6111-T4 sheet using a pinless tool. Materials Chemistry and Physics, 141(2), 768-775. https://doi.org/10.1016/j.matchemphys.2013.05.073

\section{Published in:}

Materials Chemistry and Physics

\section{Citing this paper}

Please note that where the full-text provided on Manchester Research Explorer is the Author Accepted Manuscript or Proof version this may differ from the final Published version. If citing, it is advised that you check and use the publisher's definitive version.

\section{General rights}

Copyright and moral rights for the publications made accessible in the Research Explorer are retained by the authors and/or other copyright owners and it is a condition of accessing publications that users recognise and abide by the legal requirements associated with these rights.

\section{Takedown policy}

If you believe that this document breaches copyright please refer to the University of Manchester's Takedown Procedures [http://man.ac.uk/04Y6Bo] or contact uml.scholarlycommunications@manchester.ac.uk providing relevant details, so we can investigate your claim.

\section{OPEN ACCESS}




\title{
The Effect of a Paint Bake Treatment on Joint Performance in
}

\section{Friction Stir Spot Welding AA6111-T4 Sheet Using a Pinless Tool}

\author{
${ }^{\mathrm{a}}$ Y.C. Chen, ${ }^{\mathrm{b}}$ S.F. Liu, ${ }^{\mathrm{c}}$ D. Bakavos, and ${ }^{\mathrm{d}}$ P.B. Prangnell \\ âYingchun.Chen@manchester.ac.uk, bsifangliu@ hotmail.com, \\ cdimitrios.bakavos@manchester.ac.uk, ${ }^{\mathrm{d}}$ philip.prangnell@manchester.ac.uk \\ Corresponding author: Yingchun Chen; Tel: +44 1613068847 \\ School of Materials, The University of Manchester, Grosvenor St., Manchester, M13 9PL, UK.
}

Key words: Friction stir welding; AA6111; Heat Affected Zone; Artificial Ageing

\begin{abstract}
It has been previously shown that it is possible to produce friction stir spot welds (FSSW) in thin ( $1 \mathrm{~mm}$ thick) aluminium sheet, when using a tool without a probe, which has the significant advantage of not leaving a keyhole in the weld. The aim of this paper was to investigate the effect of a post-weld paint bake cycle on the performance and precipitation behaviour of FSSW joints produced using a pinless tool, in the heat-treatable Al automotive alloy AA6111-T4, with rapid, industrially relevant, weld cycle times. It has been demonstrated that strong joints could be obtained within $<1$ second, that exhibited a nugget pull-out failure mode, and the weld strength increased further after the paint bake treatment. After the paint bake cycle the weld zone was found to be considerably harder than the parent material and this behaviour has been attributed to
\end{abstract}


the shorter delay time between welding and artificial ageing, relative to the longer pre-natural ageing time experienced by the parent sheet. With a rapid $(<1 \mathrm{sec})$ weld cycle, no hardness minima were observed in the heat affected zone (HAZ) after the paint-bake treatment.

\section{Introduction}

There is an accelerating trend in automotive manufacturing towards the greater use of light alloys, to reduce vehicle mass and achieve increasingly demanding fuel efficiency targets. Unfortunately, conventional welding processes, like resistance spot welding (RSW), are difficult to apply to aluminium (Al) alloys because of their high conductivity, low strength at elevated temperature, and tendency to degrade the electrodes.[1,2] Furthermore, other joining processes in production, such as self-piercing riveting (SPR) have high associated consumable costs [3-5].

Friction stir spot welding (FSSW) is a relatively new alternative joining method that has already been applied successfully to welding aluminium panels in automotive manufacturing by the Mazda Motor Corporation, who claim large energy (90\%) and capital investment savings (40\%), compared to RSW [6]. In a new development to this process it has recently been demonstrated, by the current authors, that it is possible to produce friction spot welds in thin (1mm thick) 6xxx aluminium automotive sheet in a rapid cycle time of less than one second, when using a tool without a probe, and still achieve good joint properties [7]. A pinless tool approach to FSSW has the advantage of not leaving a keyhole in the weld centre, which causes cosmetic and corrosion issues, and is simpler and faster than the RefillTM welding method [8].

In automotive manufacturing $\mathrm{Al}$ alloy sheets, welded in an under-aged $\mathrm{T} 4$ temper (solution treatment + natural ageing), will normally undergo a paint-bake thermal cycle (PBC) where the 
car body is heated at temperatures of $150-180^{\circ} \mathrm{C}$ to cure the paint applied in the final stage of body assembly process. This treatment increases the yield strength of heat treatable alloys, like 6111, through artificial age hardening due to the creation of more solute clusters and by increasing the density of fine precipitates within the material. However, most research on FSSW of 6xxx automotive sheet has only evaluated the properties of welds in the T4 temper condition, in which the material is originally supplied. It is thus important to understand the effect that this heat treatment operation will have on weld performance. To date, there have been few studies concerning the effect of a post-weld paint bake cycle (PBC) on the behaviour of friction stir spot welds. In one investigation, Blundell et al. [9] have reported that, even though the PBC increases the strength of the parent AA6111sheet, it reduced joint performance. More work is, therefore, needed to understand the effect of the paint bake treatment, particularly in the case of rapid, pinless, FSSW, where a stronger material temper may affect the joint failure behaviour.

The main aim of this paper was to investigate the effect of a paint bake cycle on the mechanical properties and fracture behaviour of FSSW joints produced in a typical heat-treatable AA6111T4 automotive alloy, using a pinless tool and industrially realistic short welding times of less than 1 second. This was achieved by studying the joint's performance and post-weld ageing behaviour, using lap shear tests and careful hardness measurements, supported by electron microscopy of the joints' fracture paths and their weld zone precipitation behaviour.

\section{Experimental}

All the spot welds were produced in $0.93 \mathrm{~mm}$ thick AA6111-T4 Al-automotive sheet, with no surface preparation prior to joining, using a $10-\mathrm{mm}$ diameter pinless tool with a fluted shoulder. Full details of the tool design and welding procedure can be found in ref. [7]. The welding trials were performed with a friction stir welding machine. A standard $0.2 \mathrm{~mm}$ shoulder plunge depth 
was used in all cases, as this was previously found to be the minimum required to obtain a satisfactory weld [7]. The weld coupons were produced at the centre of a $25 \mathrm{~mm}$ overlap between two 25 by $100 \mathrm{~mm}$ strips. All welding was carried out under displacement control. The plunge and rotation rate were kept constant at $2.5 \mathrm{~mm} \mathrm{~s}^{-1}$ and $2000 \mathrm{rpm}$. Two dwell times of 0.5 and 1 second were studied. When combined with the plunge and retract, this gave total weld cycle times of $\sim 0.7$ and 1.2 seconds. A tight fitting clamping plate was used with a 12-mm diameter machined hole, to increase the hydrostatic pressure under the tool and prevent lifting of the top sheet. Dissimilar alloy welds were also produced between the AA6111 sheet and a AA6082 alloy, which is a 6xxx material with a lower $\mathrm{Cu}$ content but similar mechanical properties, to reveal the weld interface position by differential etching.

The temperatures reached in the samples were measured using thermal couples inserted vertically from the backing plate into the bottom surface of Al sheets. Measurements were made at a radial distance of $2.5 \mathrm{~mm}$ from the tool centre. The thermocouple tips were mounted $\sim 0.1$ mm proud of the anvil ensuring good contact aided by the welding down force. Microhardness measurements (using a $1 \mathrm{~kg}$ load, $10 \mathrm{~s}$ dwell, and $3 \mathrm{~s}$ load application time) were made across the welds in the top sheet, at $0.5 \mathrm{~mm}$ below the top surface, immediately after welding ( $<1$ hour,) and following post-weld heat treatment (PWHT). In order to simulate the paint bake cycle (PBC) that would be used in industry, the weld samples were artificially aged at $180{ }^{\circ} \mathrm{C}$ for 30 minutes immediately after welding. The welds were tested in a lap shear configuration using a constant displacement rate of $1 \mathrm{~mm} \mathrm{~min}^{-1}$ and the maximum strength and failure energy averaged over three repeated tests for each condition. The microstructures of the weld zones were characterised by a high resolution FEI Sirion FEG-SEM on samples prepared with a gentle finishing mechanical polish, using colloidal silica, followed by light electro-polishing in $30 \%$ nitric acid 
methanol solution at $-25^{\circ} \mathrm{C}$. Fine-scale precipitation was studied by TEM using a Philips CM20 and an FEI Tecnai F30 with electro-polished samples prepared from the mid plane of the top sheet at the weld centre.

\section{Results and Discussion}

\section{Welding behaviour}

Optical images of cross-sections from the AA6111-T4 standard welds and AA6111-AA6082 interface marker experiment FSSWs, produced with dwell times of 0.5 and $1 \mathrm{sec}$. are shown in Fig. 2. For the experimental marker welds, a higher magnification view of the interface is also shown in Fig. 3. In Fig 1 the conventional AA6111 weld sections show the extent of the deformation zones; however, the etching is sensitive to changes in the precipitation behaviour within the weld zones, whereas the dissimilar alloy weld cross sections give a clearer picture of the interface position between the two sheets. The weld formation process, in FSSW with a pinless tool, has already been described in detail in ref. [7]. As discussed in this previous study, the deformation zone increases in depth with welding time, penetrating further into the bottom sheet. At the centre of the weld the join line is pushed down into the bottom sheet, and this starts to displace material from the bottom sheet sideways forming a hook. The hook formation is a relatively minor effect with short welding times (e.g. $<1 \mathrm{sec}$ ), but can become excessive for longer welding times (see [7]). In Fig. 3 (c) \& (d) good metallurgical bonding can be seen across the interface between the two sheets. Intercalated shear layers are also apparent in the 1 second weld at the weld interface and there are few signs of pores or weld defects.

Figs. $2 \& 3$ thus demonstrate that, with an appropriate tool design (see [7]), fully bonded welds can be successfully produced with dwell times of less than 1 second, with the minimum of hooking and few defects at the join line. However, discontinuous patches of oxide trails were 
seen dispersed within the welds near the edge of the bonded area. In Fig. 4 SEM images are presented that depict the oxide distribution seen at the edge of the join line, between the two sheets, in a weld produced with the shorter dwell time of 0.5 second. The edge of the weld between the top and bottom sheets can be noted to be located about $0.5 \mathrm{~mm}$ inward from the tool shoulder circumference (Fig. 4a) and this position is related to the periphery of the "bowl-shaped" plastic zone developed under the tool (Fig. 2) [7]. Even at this weld edge position, the surface oxide on the original sheets had been considerably broken up by the welding process. Moving further in towards the weld centre, the oxide remnants became more scattered (Fig. 4c) confirming that there was considerable plastic deformation at the weld interface and a strong metallurgical bond has been formed.

\section{$\underline{\text { Weld temperatures }}$}

Thermal cycles recorded in the 0.5 and 1 second welds, by thermocouples positioned in contact with the bottom of the Al base sheet, $2.5 \mathrm{~mm}$ out from the weld centre, are shown in Fig. 5. The peak temperatures measured reached $\sim 250{ }^{\circ} \mathrm{C}$ and $350{ }^{\circ} \mathrm{C}$ for the 0.5 and 1 second welds, respectively. As a cold steel backing plate was used the temperatures would be expected to be considerably higher at the top surface under the tool contact area.

\section{$\underline{\text { Joint Performance }}$}

In Fig. 6 lap shear test results are depicted for the 0.5 and 1 second pinless FSSWs measured immediately after welding and after the post-weld paint bake treatment. Typical failed test samples are shown in Fig. 7. In the as-welded condition all the joints failed by nugget pull-out and the maximum failure loads were 3.2 and $2.9 \mathrm{kN}$, for the 0.5 and 1 second welds respectively. After PWHT, the maximum failure load increased to about $4 \mathrm{kN}$, and the joints still exhibited a 
full nugget pull-out failure behaviour. The lap shear test results, therefore, showed that the application of a paint bake cycle immediately after welding led to improved weld strengths, in contrast to the results previously reported by Blundell et al. [9]. As will be discussed below, this can be explained by the PBC treatment significantly increasing the alloy yield stress in the weld zone and, thus, raising the resistance of the top sheet to ductile tearing in the nugget pull-out failure process. The average failure energies also showed encouraging results, being in the range 4.2 - 8 kN.mm. They tended to be higher for the $0.5 \mathrm{sec}$ weld, but gave larger scatter than the failure strength measurements because they were obtained from integration of the load displacement curve, making the evaluation of a trend difficult.

In agreement with the high failure energies, after the paint bake treatment, the failure mode of the joints still showed a full nugget pull-out behaviour (Fig. 7), which again indicated that a strong metallurgical bond was formed at the joint interface. Typical fracture paths seen in sections through partially failed lap shear test samples, in the as-welded condition and after the paint bake treatment - from welds produced with a dwell time of 0.5 second - are shown in Fig. 8 . These images clearly demonstrate that the failure initiated at the stress concentration associated with the gap between the bottom and top sheets at the edge of the welded area, (Fig. 4a), and then followed an upward path through the weld zone, where the top sheet had been thinned by the tool plunge. The initial deviation of the crack from the plane of the sheets was also influenced by the oxide residue in the hook region at the weld edge (shown in Fig. 4).

\section{$\underline{\text { Hardness Behaviour }}$}

When welding a heat-treatable alloy a factor that would be expected to influence joint performance in a pull-out failure is any loss of strength in the heat affected zone (HAZ), or thermomechanically affected zone (TMAZ) [7, 10], caused by over-ageing during the welding 
cycle. To assess the significance of such an effect, hardness profiles were measured across the welds, before and after the simulated paint bake treatment, at a depth of $0.5 \mathrm{~mm}$ below the top surface. In Fig. 9 hardness profiles are depicted for the 0.5 second and 1 second dwell time welds, measured immediately after welding, and following the simulated paint bake post-weld heat treatment. Immediately after welding, while in the T4 condition, the parent alloy had a hardness level of $83 \mathrm{Hv}$ and a single hardness trough was found across both weld zones. With the 0.5 second dwell time weld, the hardness distribution had a nearly flat bottomed 'U-shaped' profile and the hardness level had decreased to a minimum of $\sim 60-65 \mathrm{Hv}$ at the weld centre. The width of this softened zone was greater than the tool diameter and extended slightly outside of the TMAZ, where it rapidly recovered back to parent properties. The hardness profile for the 1 second weld was similar, but exhibited a slightly more 'W-shaped' profile with minima of $\sim 58$ Hv near the weld edges and was a little wider, owing to the higher heat input.

In contrast, when the weld hardness profiles were re-measured in the same position after the weld coupons were subjected to a simulated paint bake cycle the area across the weld, previously softened by the weld thermal cycle, was found to become substantially harder than the parent material (by $\sim 30 \mathrm{Hv}$ ) even though the parent material also increased in strength from $83 \mathrm{Hv}$ to $93 \mathrm{Hv}$ (Fig. 9). Furthermore, after artificial ageing little evidence was seen of minima at the edge of the weld areas in the hardness data. Such hardness minima typically occur at the HAZ/TMAZ border and are normally prominent in FSWs in heat treatable Al-alloys, where they give rise to a classical 'W-shaped' hardness profile, and [7, 10]. A lack of hardness minima within the weld zone is an advantage from a joint performance point of view, because failure can become concentrated within such zones of reduced yield stress [11-13]. In the FSSWs studied its absence can be attributed to the very short weld cycle employed, which limits the thermal damage, or 
overageing, experienced by the parent sheet. The resultant increase in strength found in the FSSWs across the whole weld zones, above that of the parent material, is very encouraging and has been investigated further below.

\section{Weld Zone Precipitation}

To better explain the hardness increase seen in the weld zones, described above, the precipitation behaviour in the welds was studied by electron microscopy. High-resolution SEM images from the top and bottom of the TMAZ in the 0.5 and $1 \mathrm{sec}$. dwell time welds, at a radial distance of $3 \mathrm{~mm}$ from the weld centre, are shown in Fig. 10, prior to the paint bake heat treatment. In all the samples broken-up iron rich primary particles and manganese containing dispersoids can be observed. At the bottom position, some heterogeneous grain boundary (GB) precipitation can also be seen in both welds, but the volume fraction is minimal, particularly in the case of the 0.5 second weld. This precipitation is typical of the appearance of GB equilibrium phases seen on over-ageing in welding [14,15], but is very localised to the grain boundaries. However, in the hottest position immediately below the tool shoulder, within the top sheet, there was little evidence of additional precipitation, indicating that at this position the material exceeded the solvus temperatures of both the $\mathrm{Q}\left(\mathrm{Al}_{4} \mathrm{Cu}_{2} \mathrm{Mg}_{8} \mathrm{Si}_{7}\right.$ at $\left.440{ }^{\circ} \mathrm{C}\right)$ and $\beta\left(\mathrm{Mg}_{2} \mathrm{Si}\right.$ at $\left.540{ }^{\circ} \mathrm{C}\right)$ phase in the AA6111 alloy [14]. Thermocouple measurements recorded peak temperatures at the base of the weld of about $250^{\circ} \mathrm{C}$ and $350^{\circ} \mathrm{C}$, for the 0.5 and 1 second welds, respectively. But, in FSSW with a pinless tool, a temperature gradient of $100{ }^{\circ} \mathrm{C}$ between the base of the bottom sheet (which was in contact with a cold steel backing plate) and the top of the weld (where the maximum rate of heat generation occurs) is to be expected [7]. These measurements, and the through thickness temperature gradient, suggests the peak temperatures where grain boundary precipitation was observed (i.e. at the base of the welds near the mid plane of the bottom sheet - Fig. 10) were 
close to that expected for the maximum precipitation rates of the equilibrium phases found in the AA6111 alloy, which are known to occur at around $330-400{ }^{\circ} \mathrm{C}[15]$.

The small hardness minima found in the as-welded condition in the 1 second weld data (Fig. 9) is consistent with the higher volume fraction of coarser grain boundary precipitation seen for this weld near its base in Fig 10, caused by the longer weld cycle. Overall, these observations thus confirm that, with a weld dwell times of less than 1 second, the thermal cycle was too rapid to allow a significant loss of strength from over-ageing to occur within the weld zone, except very locally near grain boundaries and then only in the HAZ/TMAZ at the edge of the weld. As a result, little solute was lost from the matrix by precipitation during welding and no hardness minima was seen in the post-paint bake hardness profiles.

In the T4 temper, after solution treatment, AA6111 automotive sheet is subjected to pre-ageing at $\sim 70{ }^{\circ} \mathrm{C}$ by warm coiling in an attempt to stabilise the alloys natural ageing response (sometimes referred to as a $\mathrm{T} 4 *$ temper). The material can then be stored at room temperature for extended periods before use, without the final properties being as greatly affected by the pre-natural ageing time (the sheet used here was $\sim 1$ year old). This pre-treatment raised the parent sheet hardness above that of a directly solution treated material to $\sim 83 \mathrm{Hv}[10,16-19]$. As mentioned above, the peak temperature experienced in the weld centre would be expected to be over 400 ${ }^{\circ} \mathrm{C}$. The softening behaviour seen immediately after welding in the hardness profiles can, therefore, be attributed to the dissolution of solute clusters and fine GPZs (Guinier-Preston zones) present in the $\mathrm{T} 4 *$ temper parent sheet [10], because the GP solvus temperature $\left(\sim 210{ }^{\circ} \mathrm{C}\right)$ was greatly exceeded [20]. As further precipitation was largely suppressed, owing to the rapid welding cycle, this resulted in a supersaturated solid solution within the weld centre that could fully respond to post-weld ageing. 
In Fig. 11 TEM micrographs and $[001]_{\mathrm{Al}}$ selected area diffraction patterns are presented from the AA6111-T4 parent material and from the centre of the 0.5 second dwell time weld, taken close to an [001] zone axis. Although no contrast from the presence of GP zones could be observed in images from the T4 parent material (Fig 11a), this is to be expected as the fine spherical GPZs and solute clusters present at this stage cannot be imaged by conventional microscopy [21]. Very weak diffuse matrix diffraction contrast was, however, observable in long exposure diffraction patterns at the $\mathrm{Al} 011$ position, which is normally systematically absent in the FCC structure (Fig. 11a). In comparison, in the weld zone no additional diffraction contrast could be detected other than from the standard Al matrix reflections (Fig. 11c). This diffraction data thus confirms that the solute clusters/GPZs present in the T4 sheet had dissolved into solid solution during welding, leading to a reduction in strength in the weld zone. However, when fully re-solution treated at $560{ }^{\circ} \mathrm{C}$ for one hour the hardness level of the parent sheet fell to around $\sim 55 \mathrm{Hv}$, which is $10 \mathrm{Hv}$ below that of the weld zone. This $\sim 10 \mathrm{Hv}$ difference, between the hardness measured in the centre of the weld zone and the solutionised parent sheet, can be attributed to the increase in yield stress derived from the fine 2 to $5 \mu \mathrm{m}$ diameter grain structure formed in the TMAZ (caused by the high level of plastic deformation experienced under the tool $[7,10]$ ).

After the paint bake treatment the hardness of the parent sheet increased from around $83 \mathrm{Hv}$ to $93 \mathrm{Hv}$, whereas in the centre of the welds, the level rose from $60-65 \mathrm{Hv}$ to $\sim 110-130 \mathrm{Hv}$, resulting in an ' $n$-shaped' hardness profile. This differential hardness increase seen after the paint bake treatment, between the parent material and within a weld centre, is much larger than can be attributed to the refined grain structure found in the weld nugget. Comparison of the TEM images in Fig. 11 (b) \& (d), shows that the precipitation behaviour in the parent sheet and weld centre developed differently following post-weld heat treatment. In both samples fine $\beta$ " needles 
can be observed, but they had a different size and density. In the [001] zone axis images the $\beta$ " needles are difficult to see edge-on and are most clearly visible as round dots, arising from the end-on cross section of the variant aligned along the $\mathrm{Al}<001\rangle$ direction parallel to the beam direction. As can be seen in Fig. 11 (b) \& (d), the paint baked weld contained a much larger volume fraction of $\beta$ " precipitates than the parent material, which were also shorter in length. Because $\beta$ " is the main strengthening phase in AA6111, this would explain the higher paint bake hardening response observed in the weld zone. In addition, in the parent sheet in Fig. 11(b) some precipitates can be seen that are rectangular in cross section and exhibit stronger contrast, which is typical of the Q' phase, whereas this phase was not observed in the paint baked welds.

It is well known that that the artificial ageing response of the 6xxx alloys in the paint bake cycle is sensitive to the prior natural ageing time following solution treatment [10, 22-24]). A number of studies have shown that prolonged natural ageing delays the artificial ageing kinetics by inhibiting the formation of $\beta$ ", the main strengthening phase $[25,26]$. In addition, it has also been shown that prolonged natural ageing can lead to the earlier formation of the Q' phase [25]. This has an important impact on the yield strength after a paint bake cycle, because the paint bake treatment is quite short relative to the full T6 temper and leaves the material in an under-aged condition, where its hardness is most sensitive to any delay in the ageing response [27]. The difference in ageing response observed between the weld zone and parent material can, therefore, be explained because the welds were artificially aged immediately after welding, whereas the base material used was over a year old. Severe deformation within the weld zone may also increase the excess vacancy concentration prior to ageing, which could potentially further accelerate the paint bake kinetics [10]. 
Finally, in practical terms it should be noted that the above observations relate to a realistic scenario, in that the paint bake cycle would be applied as part of the body fabrication process in an automotive production line, and the parent material would be subjected to a $\mathrm{T} 4 *$ temper and stored for up to 6 months prior to pressing into panels. In a real application this would thus lead to a similar situation where the weld zone in FSSWs produced with a rapid cycle time would be expected to develop a higher yield stress than the surrounding structure, because prior to the paint bake treatment a re-solutionised weld zone will experience a much shorter natural ageing time.

\section{Conclusions}

It has been demonstrated that pinless FSSW of thin gauge $(<1 \mathrm{~mm}$ thick) AA6111-T4 automotive sheet is an advantageous process. Successful welds can be produced within a weld time of less than one second that exhibit high joint strengths, no weld keyhole, and an energy intensive nugget pull-out failure mode. Furthermore, contrary to previous reports, the weld strengths were found to increase after a post-weld paint bake treatment.

With the rapid weld cycle achieved, little coarse scale heterogeneous precipitation was found in the TMAZ/HAZ and no hardness minima were observed in cross-weld hardness profiles after the paint bake treatment. Immediately after welding, rapid friction stir spot welding was found to lead to the formation of a softened zone within the TMAZ, which is caused by the dissolution of the solute clusters/GPZs present in the T4 temper parent sheet.

Following a simulated post-weld paint bake cycle, the weld zone was found to become harder than the parent material, significantly increasing the weld shear strength. The greater hardness response of the welds, compared to that of the parent alloy, has been shown to be caused by the 
weld zone exhibiting more rapid ageing kinetics during the paint bake cycle. This difference in behaviour can be attributed to the far longer pre-natural ageing time seen by the parent $\mathrm{T} 4^{*}$ sheet, compared to that of a weld produced in an automotive production line, which delays the precipitation of the main $\beta$ "strengthening phase formed in the AA6111 alloy.

\section{$\underline{\text { Acknowledgements }}$}

The authors are grateful to EPSRC for funding this research LATEST2, (EP/G022402/1), as well as Mr. Tym Burman of Novelis UK for provision of materials.

\section{$\underline{\text { References }}$}

[1] I. Lum, S. Fukumoto, E. Biro, D.R. Boomer, Y. Zhou, Electrode pitting in resistance spot welding of aluminum alloy 5182, Metall. Mater. Trans. A. 34A (2003)217.

[2] J. Peng, S. Fukumoto, L. Brown, N. Zhou, Image analysis of electrode degradation in resistance spot welding of aluminium, Sci. Technol. Weld. Join. 9 (2004)331.

[3] T.A. Barnes, I.R. Pashby, Joining techniques for aluminum space frames used in automobiles. Part I - solid and liquid phase welding, J. Mater. Process. Technol. 99 (2000)62.

[4] T.A. Barnes, I.R. Pashby, Joining techniques for aluminum space frames used in automobiles. Part II - adhesive bonding and mechanical fasteners, J. Mater. Process. Technol. 99 (2000)72.

[5] L. Han, M. Thornton, M. Shergold, A comparison of the mechanical behaviour of selfpiercing riveted and resistance spot welded aluminium sheets for the automotive industry, Mater. Design. 31 (2010)1457.

[6] H. Badarinarayan, F. Hunt, K. Okamoto, Friction stir spot welding in "Friction Stir Welding and Processing" edited by R.S. Mishra and M.W. Mahoney, ASM, Materials Park, OH (2007) 235. 
[7] D. Bakavos, Y.C. Chen, L. Babout, P.B. Prangnell, Material interactions in a novel pinless tool approach to friction stir spot welding thin aluminum sheet, Metall. Mater. Trans. A. 42A (2011)1266.

[8] M.D. Tier, T. Rosendo, C.W. Olea, C.P. Mazzaferro, F.D. Ramos, M. Bayer, J.F. Dos Santos, A.M. Da Silva, J. Mazzaferro, T.R. Strohaecker, The Influence of Weld Microstructure on Mechanical Properties of Refill Friction Spot Welding of 5042 Aluminium Alloy, Proceedings of the 7th International Symposium on Friction Stir Welding, 20-22nd May (2008), Awaji Island, Japan.

[9] N. Blundell, L. Han, R. Hewitt, K. Young, The influence of paint bake cycles on the mechanical properties of spot friction joined aluminium alloys, SAE 2006 World Congress \& Exhibition, SAE Technical paper 2006-01-0968.

[10] Y.C. Chen, D. Bakavos, A. Gholinia, P.B. Prangnell, HAZ development and accelerated post-weld natural ageing in ultrasonic spot welding aluminium 6111-T4 automotive sheet, Acta. Mater. 60 ( 2012)2816.

[11] Y. Chen, H. Liu, J. Feng, Friction stir welding characteristics of different heat-treated-state 2219 aluminum alloy plates, Mater. Sci. Eng. A. 420 (2006)21.

[12] H.J. Liu, Y.C. Chen, J.C. Feng, Effect of heat treatment on tensile properties of friction stir welded joints of 2219-T6 aluminium alloy, Mater. Sci. Technol. 22 (2006)237.

[13] Y.C. Chen, A. Gholinia, P.B. Prangnell, Interface structure and bonding in abrasion circle friction stir spot welding: A novel approach for rapid welding aluminium alloy to steel automotive sheet, Mater. Chem. Phys. 134 (2012)459. 
[14] D. Bakavos, P.B. Prangnell, Effect of reduced or zero pin length and anvil insulation on friction stir spot welding thin gauge 6111 automotive sheet, Sci. Technol. Weld. Join. 14 (2009)443.

[15] N. Kamp, A. Sullivan, J.D. Robson. Modelling of friction stir welding of 7xxx aluminium alloys. Mater. Sci. Eng. A. 467A (2007)246.

[16] W.F. Miao, D.E. Laughlin, Precipitation hardening in aluminum alloy 6022, Scripta. Mater. 40 (1999)873.

[17] M. Murayama, K. Hono, Pre-precipitate clusters and precipitation processes in Al-Mg-Si alloys, Acta. Mater. 47 (1999)1537.

[18] S. Esmaeili, D.J. Lloyd, W.J. Poole, A yield strength model for the Al-Mg-Si-Cu alloy AA6111, Acta. Mater. 51 (2003)2243.

[19] S. Esmaeili, D.J. Lloyd, W.J. Poole, Modeling of precipitation hardening for the naturally aged Al-Mg-Si-Cu alloy AA6111, Acta. Mater. 51 (2003)3467.

[20] G.A. Edwards, K. Stiller, G.L. Dunlop, M.J. Couper, The precipitation sequence in Al-MgSi alloys, Acta. Mater. 46 (1998)3893.

[21] M. Murayama, K. Hono, W.F. Miao, D.E. Laughlin, The effect of $\mathrm{Cu}$ additions on the precipitation kinetics in an $\mathrm{Al}-\mathrm{Mg}-\mathrm{Si}$ alloy with excess $\mathrm{Si}$, Metall. Mater. Trans. A. 32A (2001)239.

[22] S. Kleiner, C. Henkel, P. Schulz, P.J. Uggowitzer, Paint bake response of aluminium alloy 6016, Aluminium. 77 (2001)185.

[23] J.D. Bryant, The effects of pre-aging treatments on aging kinetics and mechanical properties in AA6111 aluminum autobody sheet, Metall. Mater. Trans. A. 30A (1999)1999. 
[24] L. Zhen, S.B. Kang, The effect of pre-aging on microstructure and tensile properties of AlMg-Si alloys, Scripta. Mater. 36 (1997)1089.

[25] X. Wang, W.J. Poole, S. Esmaeili, D.J. Lloyd, J.D. Embury, Precipitation strengthening of the aluminum alloy AA6111, Metall. Mater. Trans. A. 34A (2003)2913.

[26] Y. Takaki, T. Masuda, E. Kobayashi, T. Sato, Effects of pre-aging condition on multi-step aging behavior in Al-Mg-Si alloy, 13th International Conference on Aluminum Alloys (ICAA13) Edited by: Hasso Weiland, Anthony D. Rollett, William A. Cassada, TMS (The Minerals, Metals \& Materials Society).(2012)1107.

[27] S. Johansson, J. Kanesund, A study of the influence of plastic pre strain in different directions before aging of extruded and hydro formed material on the mechanical properties of AA6063, 13th International Conference on Aluminum Alloys (ICAA13) Edited by: Hasso Weiland, Anthony D. Rollett, William A. Cassada, TMS (The Minerals, Metals \& Materials Society).(2012)1727. 


\section{Figure captions}

Figure 1. (a) Schematic diagram of the friction stir spot welding process with a pinless tool and (b) thermal image obtained during welding with a 1 second dwell time. The design of the tool is shown in the insert.

Figure 2. Cross-sections of typical pinless AA6111-T4 FSSWs, produced with short dwell times of (a) 0.5 and (b) 1 second, compared to interface marker alloy welds between AA6111 and AA6082 made, with the same welding times (c) and (d).

Figure 3. Cross-sections of the weld interface at a higher magnifications for welds produced between the AA6111and AA6082 alloy sheets; (a) 0.5 and (b) 1 second dwell time.

Figure 4. SEM images showing the oxide distribution at the edge of the bonded area in a 0.5 second weld; (a) the end of the join line at low magnification, (b) higher magnification image from the position indicated in (a); (c) \& (d) high magnification images from the positions shown in (b).

Figure 5. Thermal cycles recorded by thermocouples positioned below the weld zone in contact with the bottom sheet base, $2.5 \mathrm{~mm}$ from the weld centre; for 0.5 and 1 second dwell time welds.

Figure 6. Average lap shear test results, for AA6111 pinless tool FSSW joints, tested in an aswelded condition and after PWHT, with weld dwell times of 0.5 and 1 second.

Figure 7. Fractured lap shear samples in the as-welded condition and after the post-weld paint bake cycle (PBC), for welding dwell times of (a) 0.5 and (b) 1 second.

Figure 8. Cross sections from interrupted lap shear tests of 0.5 second dwell time welds showing the fracture path, in (a) the as-welded condition and (b) after the paint bake treatment. 
Figure 9. Hardness profiles measured across the centre of the 0.5 and 1 second dwell time welds immediately after welding and following the post-weld paint bake treatment.

Figure 10. Back scattered electron SEM images of the coarser-scale precipitation seen at the top and bottom of the TMAZ, for weld dwell times of (a) 0.5 and (b) 1 second, at a radial distance of $\sim 3.5 \mathrm{~mm}$ from the weld centre. The location of the images is shown in the insert.

Figure 11. TEM micrographs and [001]Al zone axis SAD patterns for; the AA6111 parent material (a) in the T4 temper and (b) after the paint bake PWHT, and from the centre of a 0.5 second dwell time weld (c) in the as-welded condition, and (d) after post weld heat treatment. 

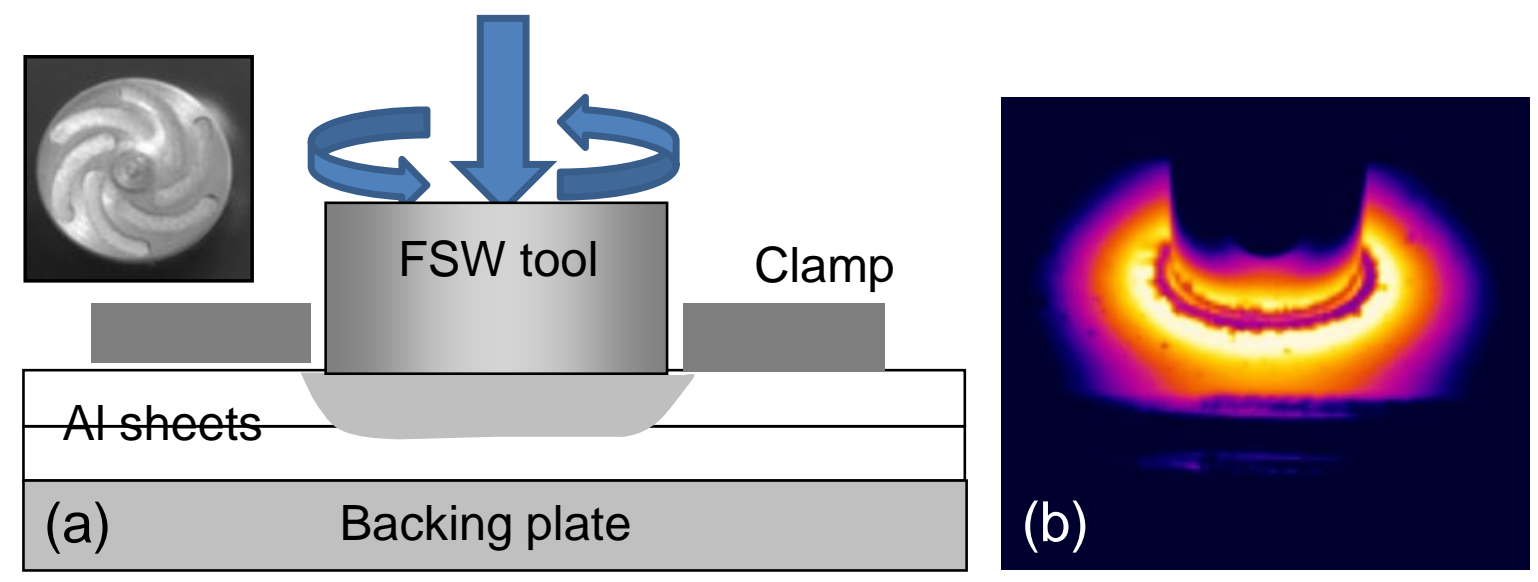

Figure 1. (a) Schematic diagram of the friction stir spot welding process with a pinless tool and (b) thermal image obtained during welding with a 1 second dwell time. The design of the tool is shown in the insert. 

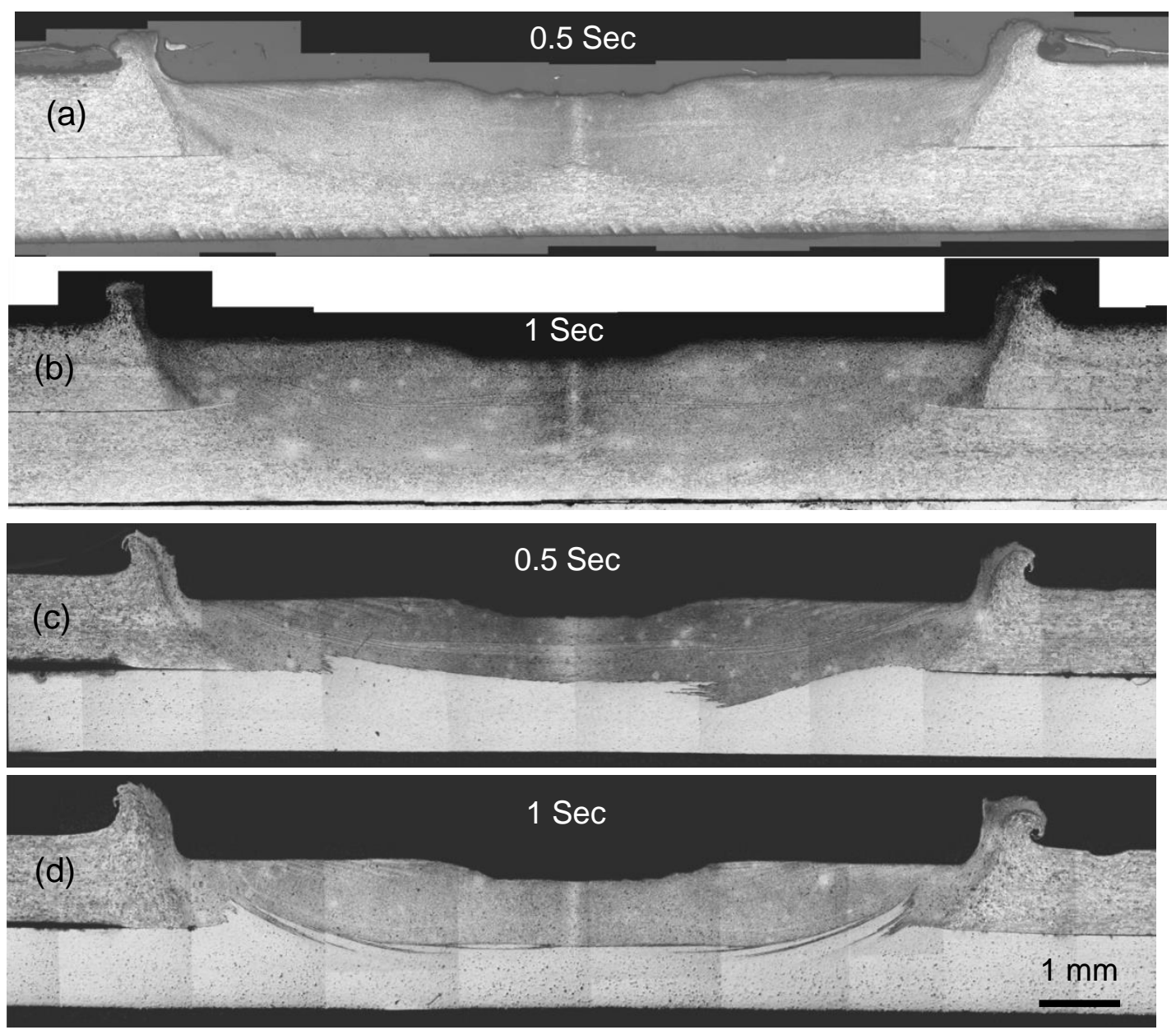

Figure 2. Cross-sections of typical pinless AA6111-T4 FSSWs, produced with short dwell times of (a) 0.5 and (b) 1 second, compared to interface marker alloy welds between AA6111 and AA6082 made with the same welding times (c) and (d). 

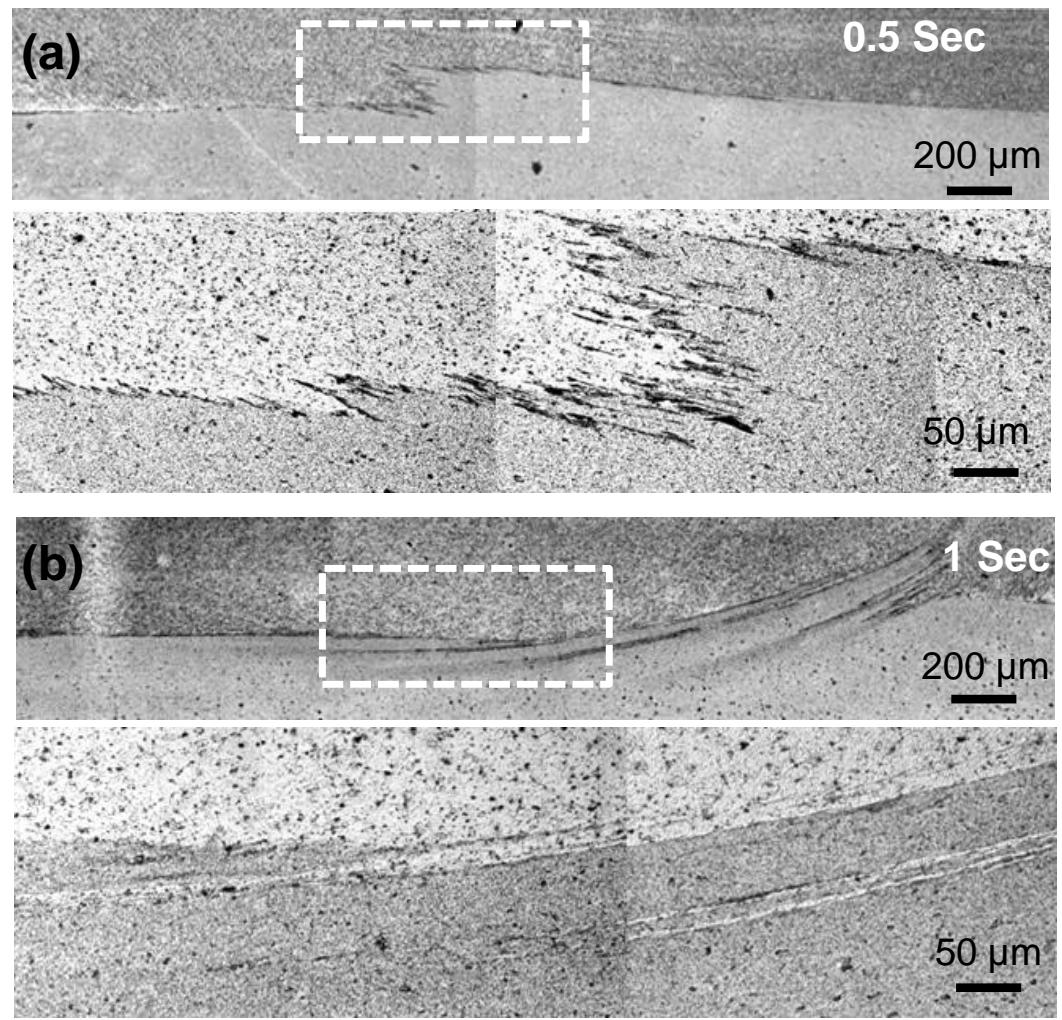

Figure 3. Cross-sections of the weld interface at a higher magnifications for welds produced between the AA6111and AA6082 alloy sheets; (a) 0.5 and (b) 1 second dwell time. 

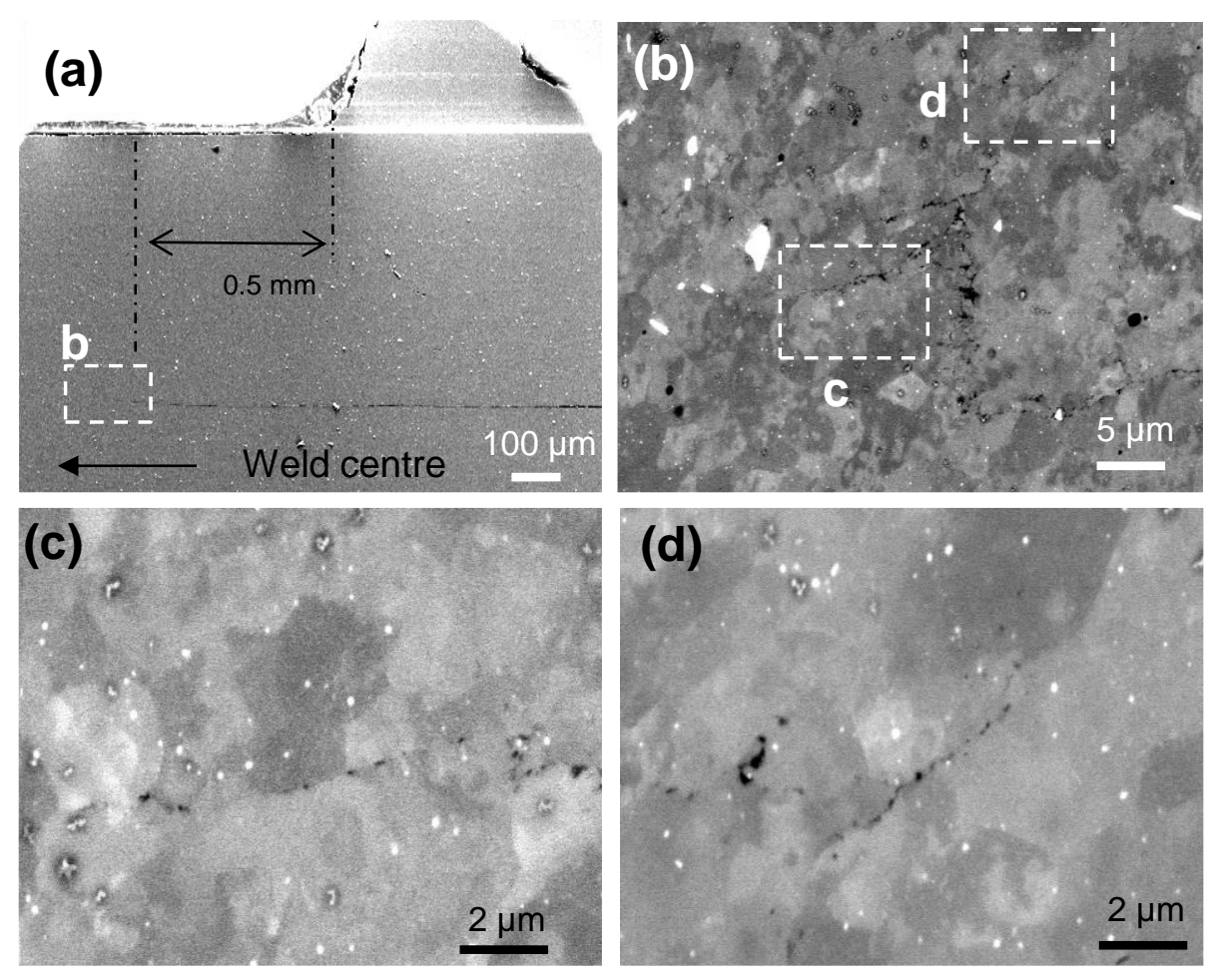

Figure 4. SEM images showing the oxide distribution at the edge of the bonded area in a 0.5 second weld; (a) the end of the join line at low magnification, (b) higher magnification image from the position indicated in (a); (c) \& (d) high magnification images from the positions shown in (b). 


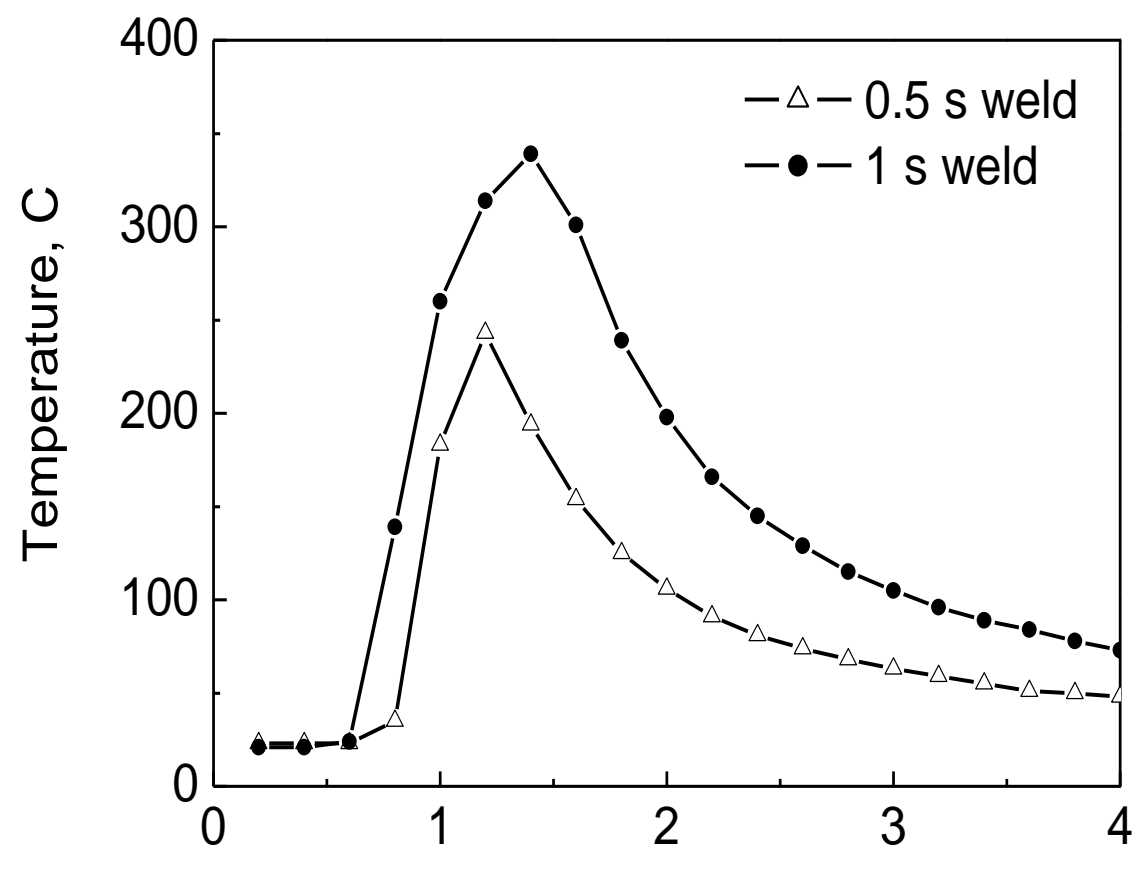

Time, $s$

Figure 5. Thermal cycles recorded by thermocouples positioned below the weld zone in contact with the bottom sheet base, $2.5 \mathrm{~mm}$ from the weld centre; for 0.5 and 1 second dwell time welds. 


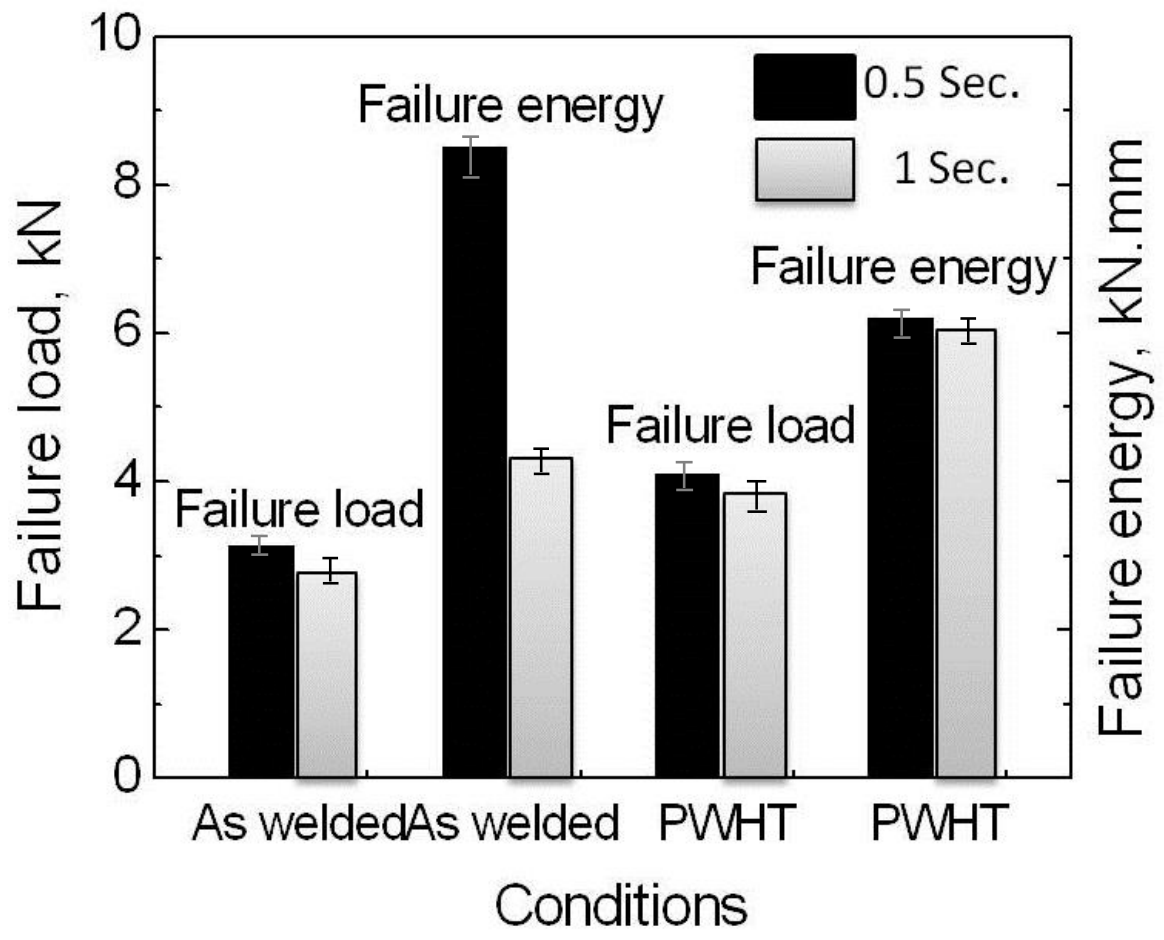

Figure 6. Average lap shear test results, for AA6111 pinless tool FSSW joints, tested in an as-welded condition and after PWHT, with weld dwell times of 0.5 and 1 second. 

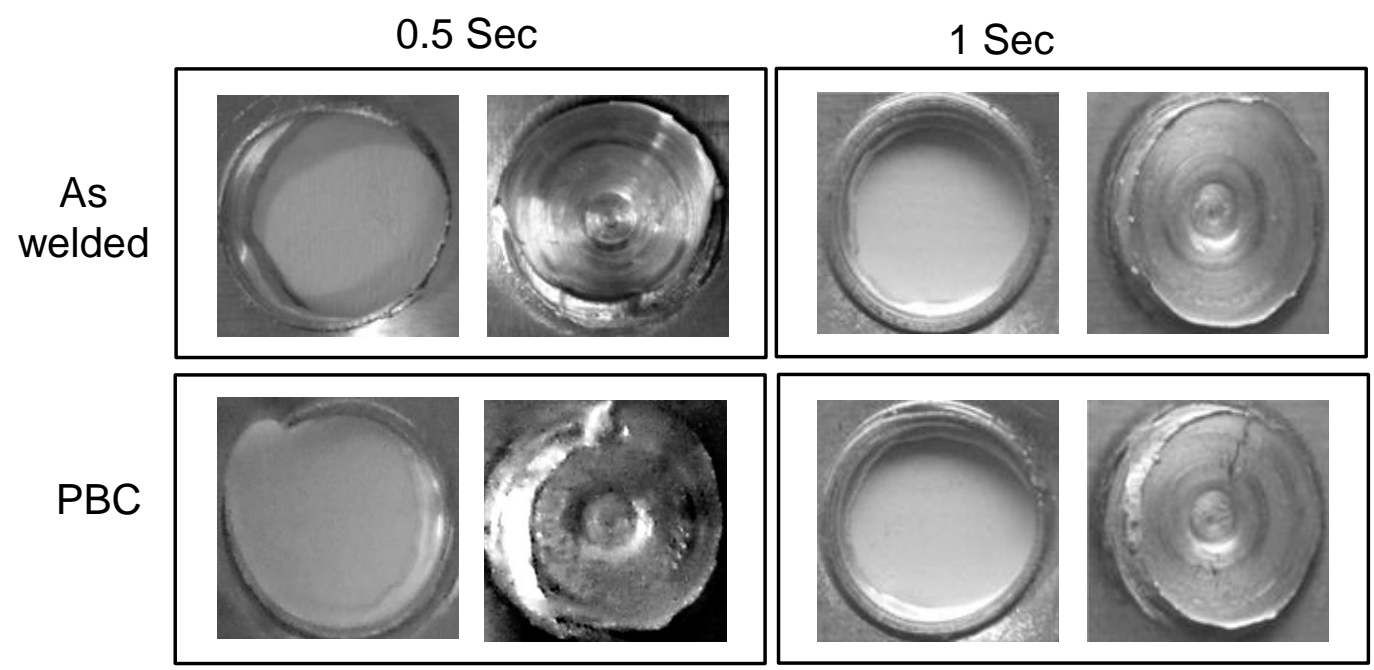

(a)

(b)

Figure 7. Fractured lap shear samples in the as-welded condition and after the post-weld paint bake cycle (PBC), for welding dwell times of (a) 0.5 and (b) 1 second. 


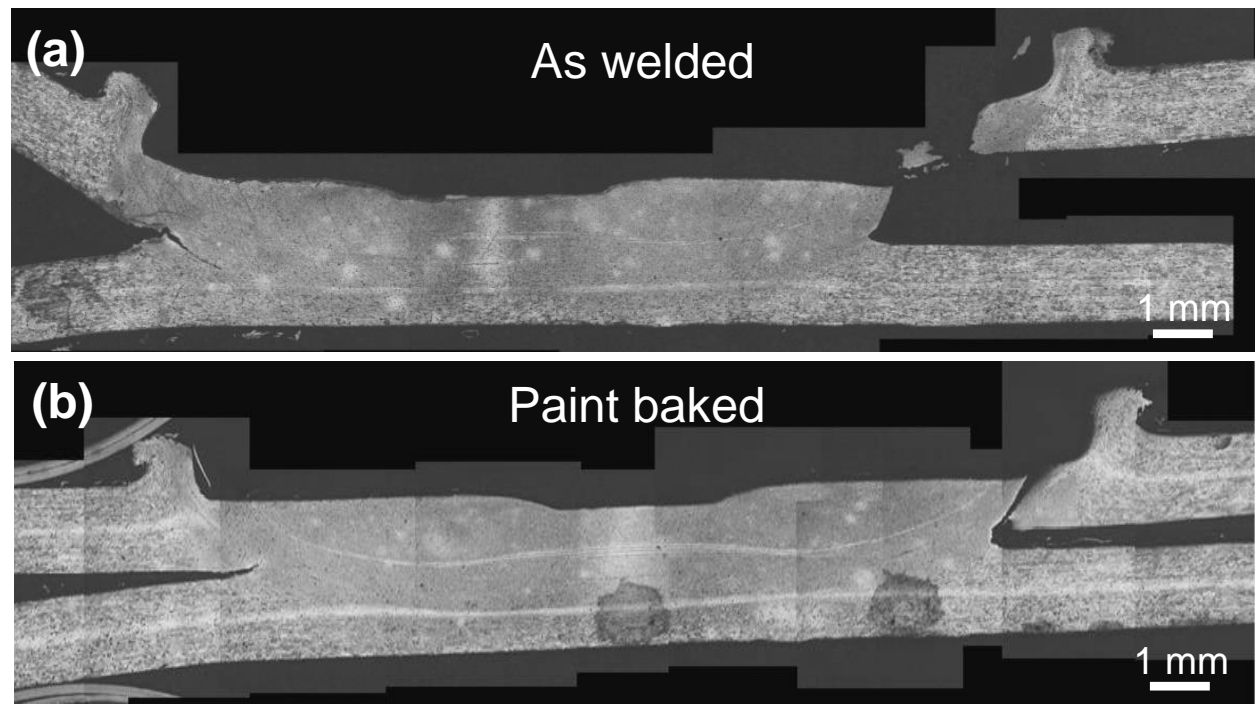

Figure 8. Cross sections from interrupted lap shear tests of 0.5 second dwell time welds showing the fracture path, in (a) the as-welded condition and (b) after the paint bake treatment. 


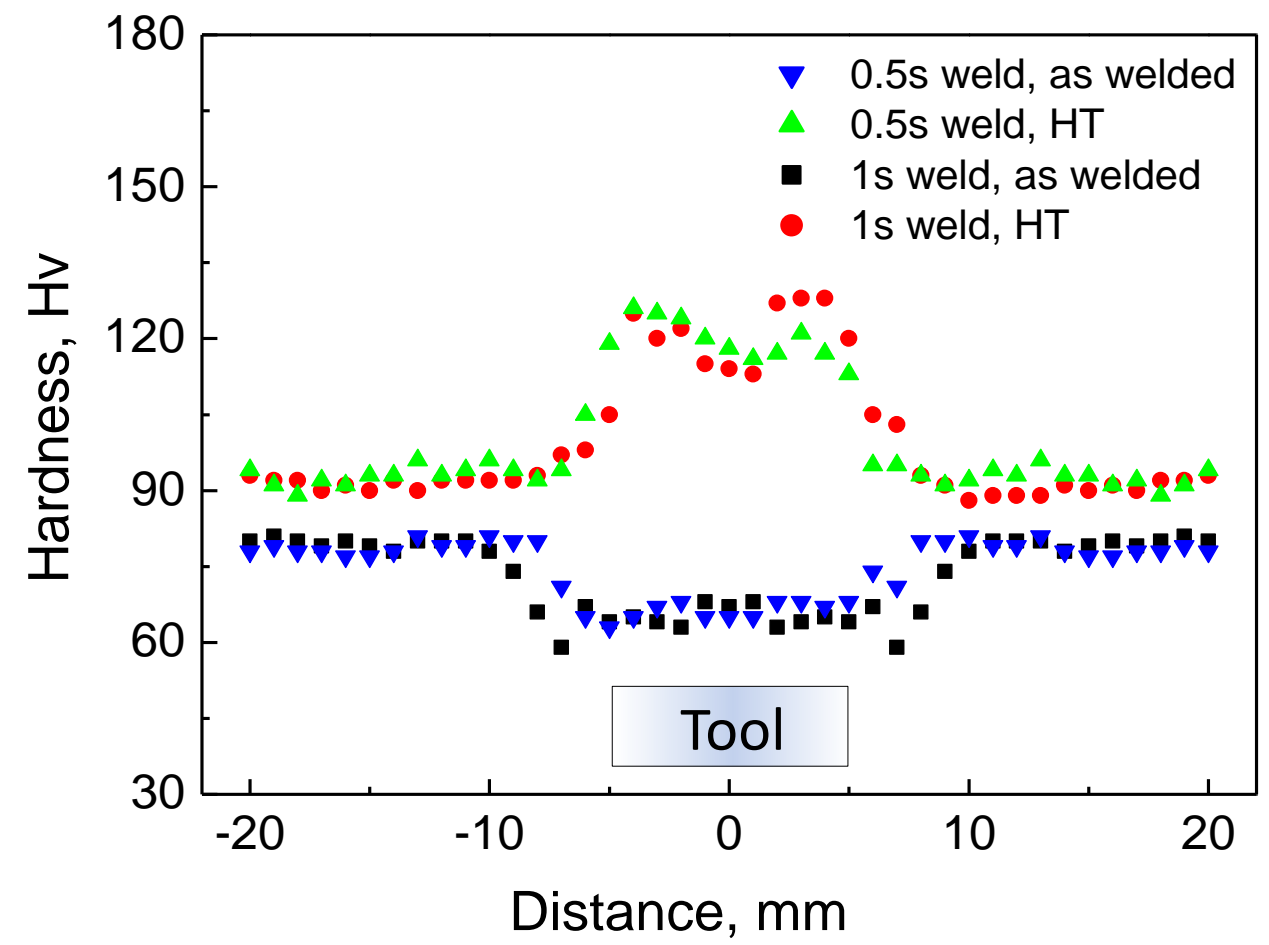

Figure 9. Hardness profiles measured across the centre of the 0.5 and 1 second dwell time welds immediately after welding and following the post-weld paint bake treatment. 

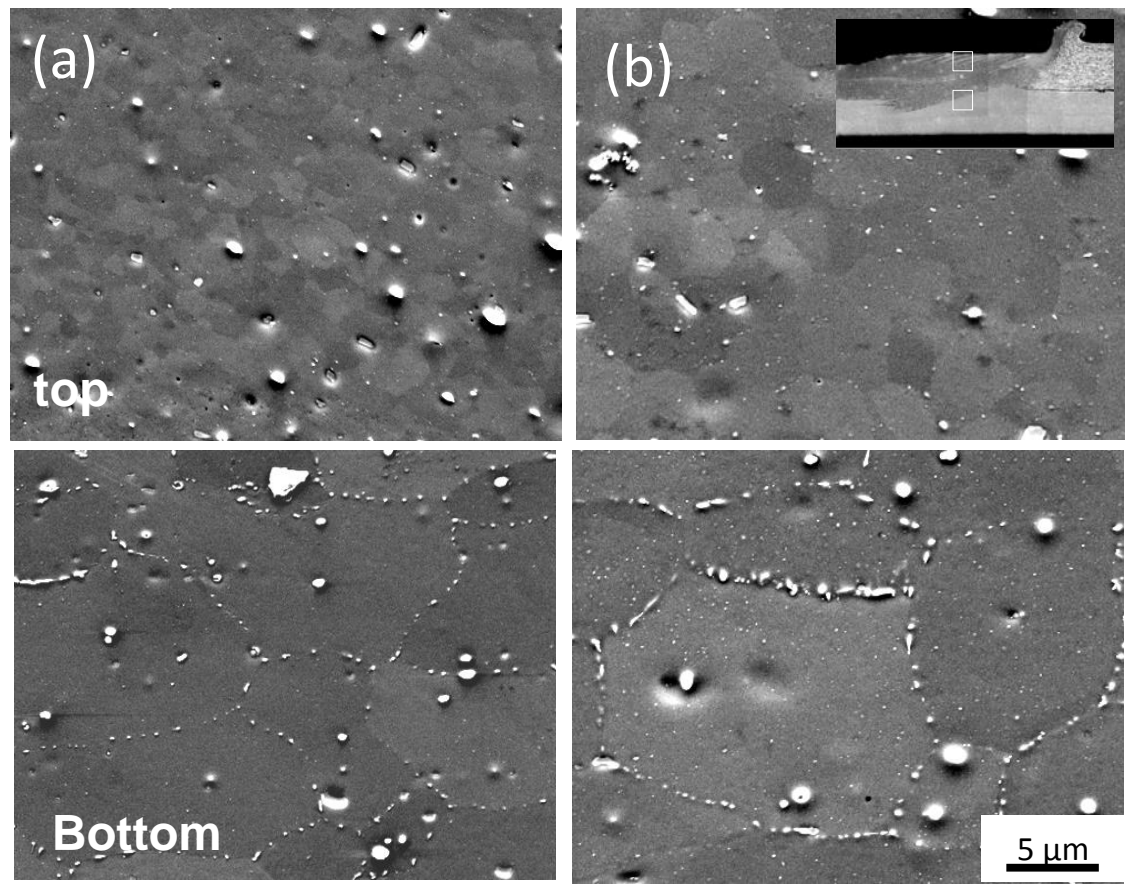

Figure 10. Back scattered electron SEM images of the coarser-scale precipitation seen at the top and bottom of the TMAZ, for weld dwell times of (a) 0.5 and (b) 1 second, at a radial distance of $\sim 3.5 \mathrm{~mm}$ from the weld centre. The location of the images is shown in the insert. 

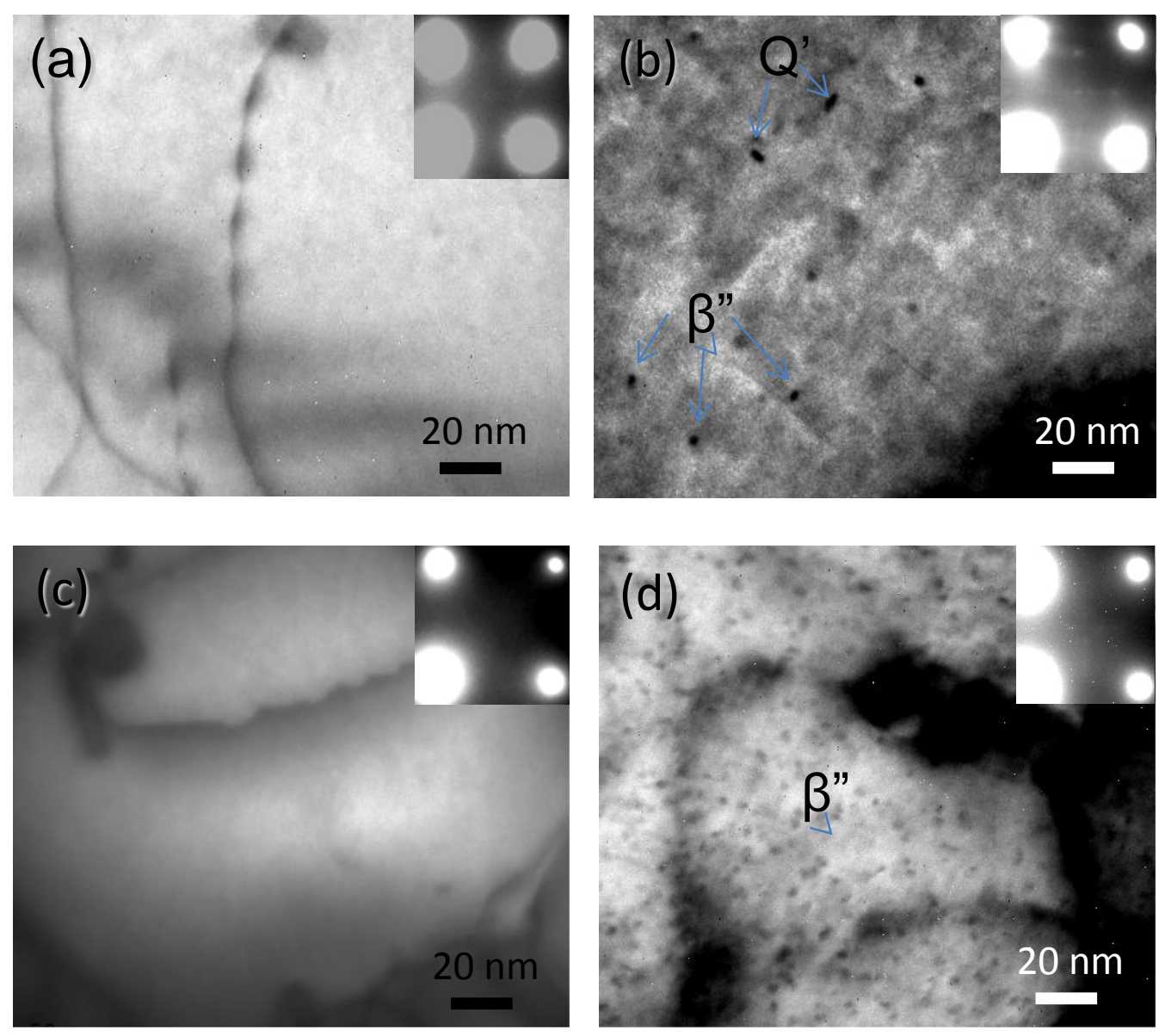

Figure 11. TEM micrographs and [001]AI zone axis SAD patterns for; the AA6111 parent material (a) in the T4 temper and (b) after the paint bake PWHT, and from the centre of a 0.5 second dwell time weld (c) in the as-welded condition, and (d) after post weld heat treatment. 